\title{
Study of Stock Markets and Investor Behaviour: Case of the \\ Casablanca Stock Exchange
}

\author{
Dahhou Nabil $^{1 *}$ Kharbouch Omar $^{2}$ \\ PhD Scholar ${ }^{1}$, Professor $^{2}$ \\ Laboratory of Economics and Management of Organisations \\ Faculty of Economics and Managements \\ Ibn Tofail University-Kénitra
}

Morocco

\begin{abstract}
The emergence of a new stream of research, behavioral finance, linking market behavior and human psychology, seeking to study cognitive biases related to investor behavior that are not explained by traditional financial theory, has opened up several avenues of research related to the behavior of stock market actors and their effects on stock markets. Our empirical study focuses, on the one hand, on the identification of the stock market crises that affected the Casablanca Stock Exchange during the period 2000-2020 and, on the other hand, on the measurement of investors' sentiment on the Moroccan stock market, to verify that the indicator of investors' sentiment is consistent with stock market crises and to find that investors' sentiment is at the origin of the Moroccan stock market crises as defined by Granger. This provides new evidence on the important role played by investor sentiment in the transmission of stock market crises.
\end{abstract}

Key Words: Behavioural finance, Investor sentiment, Stock market crises, Financial Econometrics.

\section{INTRODUCTION}

Investment is not a purely rational decision, based solely on analysis fundamentals which are rates, benefits or the market movement. In fact, the traditional theory of financial markets which has been successful for several decades has lately become unable to explain diverse cognitive biases linked to investors' behavior that distress financial markets. The questioning of the financial market efficiency leads to the failures of financial models and theory. Investors are not always rational and the markets are not often efficient (prices do not always accurately reflect information). Stock market crises have deepened such questioning; they are characterized by a rapid and sharp drop in prices, and a strong growth in trading volumes.

Psychologists have shown that market operators' real behavior cannot be explained by basic economic theories. Operators' expectations are not objective and their choices are influenced by external factors. In fact, several researchers have long considered that psychology has its impact and a role in determining and analyzing the market behavior. The most widespread idea in this field is that the study of psychology and other sciences will help inform and analyze the efficiency of financial markets. It will help understand several phenomena such as trading market anomalies, stock market bubbles and crashes that led to the emergence of behavioral financial which connects market behavior with human psychology. The study of behavioral finance is as important as it permits to understand the 
irrationality of human behavior and sheds light on certain anomalies that yet are not explained by classic financial theory.

The economic and financial theory assumes that the individual is rational. Psychologists argue that it is quite the opposite and that the individual's decisions are often biased by feelings and wrong reasoning. More and more analysts admit the effect of other factors such as over confidence, memes, nominal anchors and other heuristics... on the building up financial courses. The analysis of these phenomena will allow us to get a new insight of the financial market and better understand its mechanisms.

This paper is broadly part of behavioral literature and permits to bring about more insight on the role and contribution of the sentiment of Moroccan investors to the development of stock market crises.

Two parts are proposed to examine this issue: the first is a theoretical approach which explains the contribution of behavioral finance to crises analysis, based on literature; we will study the link between market behavior and human psychology and identify research hypotheses. The second part is empirical and is dedicated to define a sample and the retained variables as well as their measurements, the presentation of the statistical methods used and their results so as to conclude the validation of the research hypotheses.

\section{LITERATURE REVIEW AND HYPOTHESIS DEVLOPMENT}

The field of behavioral finance has experienced a considerable development during the last decades. This field covers two concepts of psychology and finance. It aims at establishing a more detailed model of investor behavior. The advantage of behavioral finance lies in highlighting the function of human thinking and the psychological characteristics of investors. The model it proposed relates market behavior to human psychology.

Investor psychology literature considers perspective theory that was proposed by Kahneman and Tversky (1979) [1] as a descriptive and pertinent model of decision making in an uncertain and risky situation. In fact, Kahneman and Tversky (1979) propose an alternative study that focuses on proving a totally irrational behavior that investors bring to the market. According to these two writers, investors are prey to many psychological factors that weaken their logical reasoning and lead them to embrace actions that are contradict rationality hypothesis.

The link between investors' emotions and valuing financial assets has long been important subjects of debate in finance, hence the existence of risky valued feeling in financial markets. The concept of investor feelings must be defined before dealing with further details. In fact, sentiment represents the investors' expectations and ere not justified by fundamentals. An optimistic (pessimistic) investor expects that security yields increase (decrease) in accordance to what fundamental indicators can explain. In other words, defining sentiment is identifying an optimistic (pessimistic) investor without being informed about the good (bad) economic reasons behind being so.

Several studies modelized the role of investors' sentiment in financial markets such as: Black (1986) [2], De Long and Al (1990) [3], Daniel, Hershleifer and Subrahmanyam (1998) [4] and Barberis, Shleifer and Vishny (1998) [5]. Generally, the models assume the existence of two types of investors: The arbitrageurs (professionals) and the noise traders (particulars). The first are supposed to know the fundamental value of assets, the second are irrational and/ or less informed investors.

During the two last decades, literature about behavioral finance has developed in a spectacular way. Literature that deals with psychology as a defining factor of the irrational behavior of investors. The behavioral theory claims that investors do not take decisions in a rational way, but apply their judgment because they are unable to analyses and proceed information. Shiller (1981) [6] is one of the first pioneers to have introduced efficiency anomalies in his studies He suggests that these anomalies depend on the investor psychology state. In fact, behavioral finance recalls the human behavior irrationality such as heuristics, overconfidence, memes, minimal anchors, emotions, risk aversion...

Studies in psychology and behavioral finance were reviewed to show if investors react in a way that induces the formation speculative bubbles in financial markets. Shleifer (2000) [7] sees that behavioral finance attributes irrational 
behavior more to investors who are less informed and have incomplete or inaccurate data about the financial market than to professional ones.

The contribution of behavioral finance to a better understanding of how really financial markets operate is undeniable. Behavioral finance in particular studies the cognitive biases and manipulation tactics that can affect the economic rationality.

Researchers in finance concentrate mainly on the market performance (prices, volumes, dividends, results, etc.) On the other hand, few researchers give little attention to the factual actors of the market performance: investors, traders, portfolio managers...

Thaller (1999) [8] in his article "The End of Behavioral Finance" sees that there will be no finance than the "behavioral", it cannot be dismissed and any economist who does not include the behavior dimension is evidently irrational. Behavioral finance is one of the most important approch that represents an alternative to efficient market theory. Moreover, Margot (2004) [9] thinks the contribution of behavioral finance as revolutionary and permits a better understanding of recurrent investors mistakes.

There are numerous definitions of behavioral finance, but there is an obvious link between them. Thaller (1993) [10] defines behavioral finance as a simple "open mindedness". So as to solve an empirical problem (financial), you have to determine the state or the situation in which some economic operators act in a less important way than that of the rational group agents.

Lintner (1998) [11] defines behavioral finance as the study of the individual psychology when he or she analyses and acts while taking investment decisions.

Olsen (1998) firmly states that behavioral finance does not attempt to define a rational behavior or a label decision, but tries to understand the systematic and financial implications related to the market and to the psychological process of decision making. It is important to note that up to now, there is no present unified theory of behavioral finance. Olsen (1998) pinpoints that most of the propositions made in the literature, the manner to identify behavioral decisions show that it is preferable to have systematic effects on the market behavior [12].

Shiller (2003) [13] notes that "The collaboration between finance and other sciences that has become as behavioral finance has led to a profound deepening of our knowledge of financial markets"

Mangot (2004) [9] supports the statement that behavioral finance, issued from psychology perspectives confrontation and finance, strives to shed light on what motivates investors' decisions, and it explains how emotions interfere in taking them.

Sewell (2007) [14] defines behavioral finance as "the study of the influence of psychology on investors' behavior and the subsequent impact on the market". This definition specifies two research paths in behavioral finance:

- The first path is concerned with the interference of the individual's emotions and feelings with financial decisions. This course has shown the influence of emotions and different feelings on the process that investors adopt in taking their investment decisions. It has also shaped several types of investors' feelings such as optimism, pessimism, overconfidence, regret.... It has tried to shape them into models in the financial market.

- The second path was geared towards social interactions in financial markets. This social component of financial decisions is not less important. Communication between individuals sometimes contributes to homogeneity, as preached by the efficiency theory. The problem of confronting social models and the fear to take the wrong options lead people to put limits to other agents' behavior. Other social elements have been detected in financial markets such as informational cascade, group reflection and polarization... 
The study of financial markets behavior is in the core of behavioral finance, it makes it differ from classic and standard financial theory which maintains the concept that markets attain the most possible economic balance as if they follow purely rational rules. In practice, behavioral finance is the study of:

- How agents (investors, borrowers, etc.) take decisions, their behavioral problems in particular. It is about micro behavioral finance or psychological behavioral finance, or simply psychological finance.

- The effects of these behavior biases on the financial markets in the form of price and yield anomalies. It is about macro behavioral finance or quantitative behavioral finance.

Behind this academic goal are two concrete objectives:

1. Make investors aware of their personal failings.

2. Enlighten them on the effects on the market of the shortcomings of various investors.

Coudert and Gex (2006) [15] used Morgan's metrics to measure risk aversion (1999) and Lynch (2003). The tests carried out show that risk aversion tend to increase before crises. In other words, measurement indicators are highly important in regressions explaining periods prior to financial crises. Their growth also increases the probability of a crisis. This makes it interesting to study the relationship between crises and sentiment in the Moroccan stock market. These studies allow to verify the accuracy of the following hypothesis:

H1: Investor sentiment influences stock market crises

Reggiani (2018) [16] sees the stock market crisis as a phenomenon characterized by a sharp drop in asset prices, known as a stock market crash. The crisis is caused by an increase in transaction volumes and a decline in stock market indices. This definition will be applied empirically to the Casablanca Stock Exchange to understand the crises that hit Morocco between 2000 and 2020.

First, we will assess the crises that affected the Moroccan stock exchange over the period 2000-2020, based on the study of the evolution of transaction volumes and the decline of the stock exchange index. Then, we will evaluate the concordance and the causal link between the stock market crises and the sentiment of the Moroccan investor.

\section{METHODOLGY}

\subsection{Sample Definition}

This work states that market behavior is explained by human psychology. First of all, we will study the crises that affected the Tunisian stock market over the period from 1998 to 2008. Then we will assess the concordance and causal link between the stock market crises and the sentiment of the Moroccan investor.

Our study was based on all companies listed on the Casablanca Stock Exchange over the period from 2000 to 2020, this sample has been subject to several restrictions, and several categories of companies have then been withdrawn.

Other companies with ambiguous or imprecise information are excluded.

The final recognized sample is composed of 40 listed companies from different sectors of activity, and the data is obtained from the Casablanca Stock Exchange website. (www.Casablanca-Bourse.com)

\subsection{Definition of study variables}

The link between investor sentiment and the valuation of financial assets has long been the subject of an important debates in behavioral finance, hence the existence of a valued sentient risk in financial markets.

This phase consists in linking theoretical concepts to data, by translating the theoretical conceptual definition into one or more empirical elements illustrating this definition or dimension. 


\subsubsection{Definition of dependent variables}

It has been hypothesized that the explanatory variable for this work is investor sentiment. Because of the inability to observe the subjective and personal nature, many proxies have been proposed in the literature to measure or at least design investor sentiment. There are two main sets of measures: direct measures and indirect measures.

Direct measures represent measures generally obtained from surveys and questionnaires. For example, the American Association of Retail Investors prepares a questionnaire every week to sample investors with 125 to 500 members. The questionnaire focuses on investor opinions and market trends over a six-month period. Fisher and Statman (2003) [17] and Brown and Cliff (2004) [18] have used these surveys.

Indirect measures are generally financial indicators that can be interpreted as upward or downward trends. However, there is always an interest in these indicators in empirical research to measure the investor sentiment.

We will use indirect indicators to measure investor sentiment. These indicators can better capture market strength and performance, and thus reflect investor optimism or pessimism. Brown and Cliff (2004) come up with a big number of indirect confidence indicators. We will limit ourselves to measurable indicators in Casablanca stock exchange. These indicators are:

- The index sent 1: this ratio is equal to the number of securities that have experienced a price increase divided by the number of securities that have experienced a price decrease during the year (n)

$$
\operatorname{sent} 1=\frac{A D V_{t}}{D E C_{t}}
$$

With:

ADV t: the number of securities that have experienced a price increase at date $t$.

DEC $t$ : the number of securities that have experienced a price decrease at date $t$.

- The index sent 2: The interest of these indicators is to study the potential for change in market trends. It is used as an indicator of investor sentiment. The second indicator is as follows:

$$
\text { Sent } 2=\frac{H I}{L O}
$$

With:

HI: the number of new increases.

LO: The number of new decreases.

\subsubsection{Definition of independent variables}

Within the framework of this research the variable to be explained is the stock market index (MASI), in fact, the crisis is due to the decrease in stock market indices and an increase in transactions.

\section{RESULTS AND DISCUSSION}

This section allows us to present in a synthetic way the statistical methods used in order to test our hypothesis concerning the contribution of investor sentiment to the development of stock market crises. First of all, we will measure the crises that have affected the stock market over the period from 2000 to 2020 . This is based on the study of the evolution of the MASI index and the analysis of the volume of transactions over this period. Then we will test the relationship and the causal link between the variables; the general regression model is in temporal series. 
International Journal of Advances in Scientific Research and Engineering (ijasre), Vol 7 (3), March -2021

\subsection{The concordance between crises and feelings}

The following graphs illustrate the MASI stock market index and trading volume over the period from 2000 to 2020.

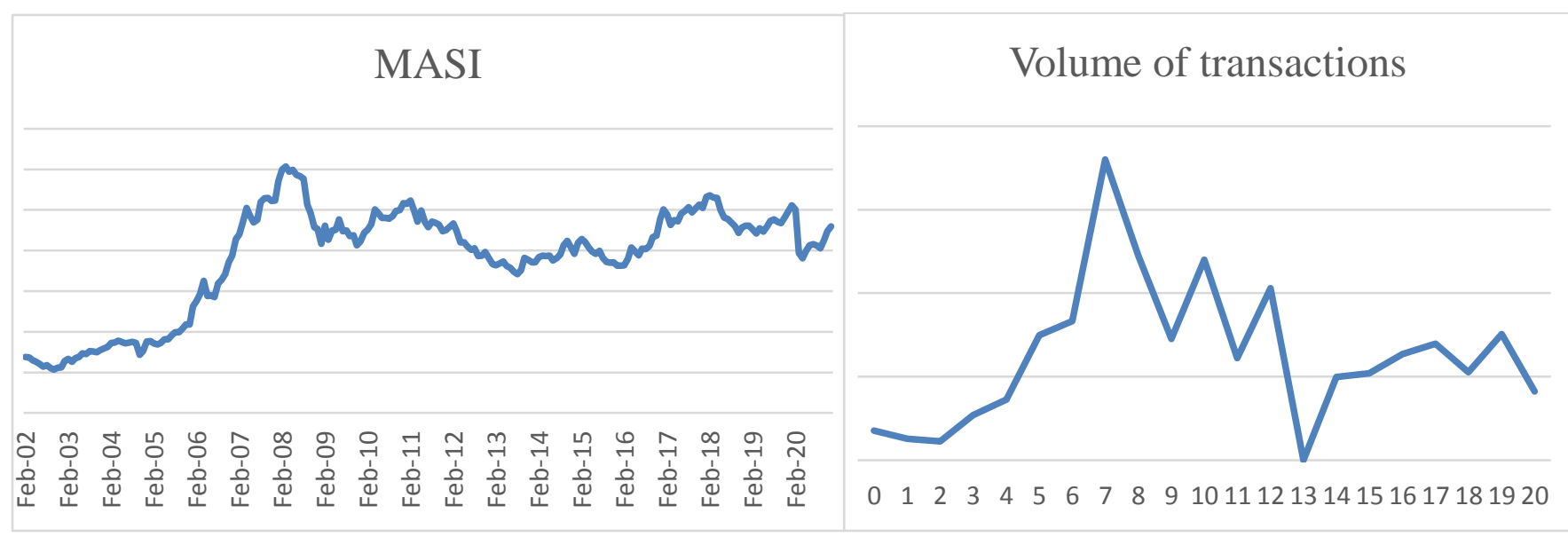

Figure 4.1: Evolution of MASI index and the volume of transactions in the Moroccan Stock Markets

Both graphs show a decrease in the stock market index between the years 2002; 2009; 2011; 2011-2012 and 20192020, while the volume of transactions has increased over the same periods. This explains the effects of the Internet crisis of 2001, the subprime crisis of 2008 which affected Morocco a little later because of its low insertion in global finance. the February 20, 2011 movement followed a wave of protests and revolutions in other countries in North Africa and the Middle East known as the Arab Spring and finally in 2019, the health crisis.

\subsubsection{Measurement of crises on the Moroccan stock market}

To empirically test the concordance and the causal link between stock market crises and investor sentiment, we will first measure the sentiment of the Moroccan investor. To do so, we will use the SENT1 and SENT2 ratios as indicators.

Over a period of 20 years, we have measured the stock prices of Moroccan companies that are listed on the stock exchange during this period. Subsequently, we summarized in a table the variations of these courses from one year to another, to finally get to calculate the indicators of measures of sentiment of Moroccan investors. the results obtained from this research allow us to conclude that the indicators of sentiment fall in the years of the crises presented in the graph below: 


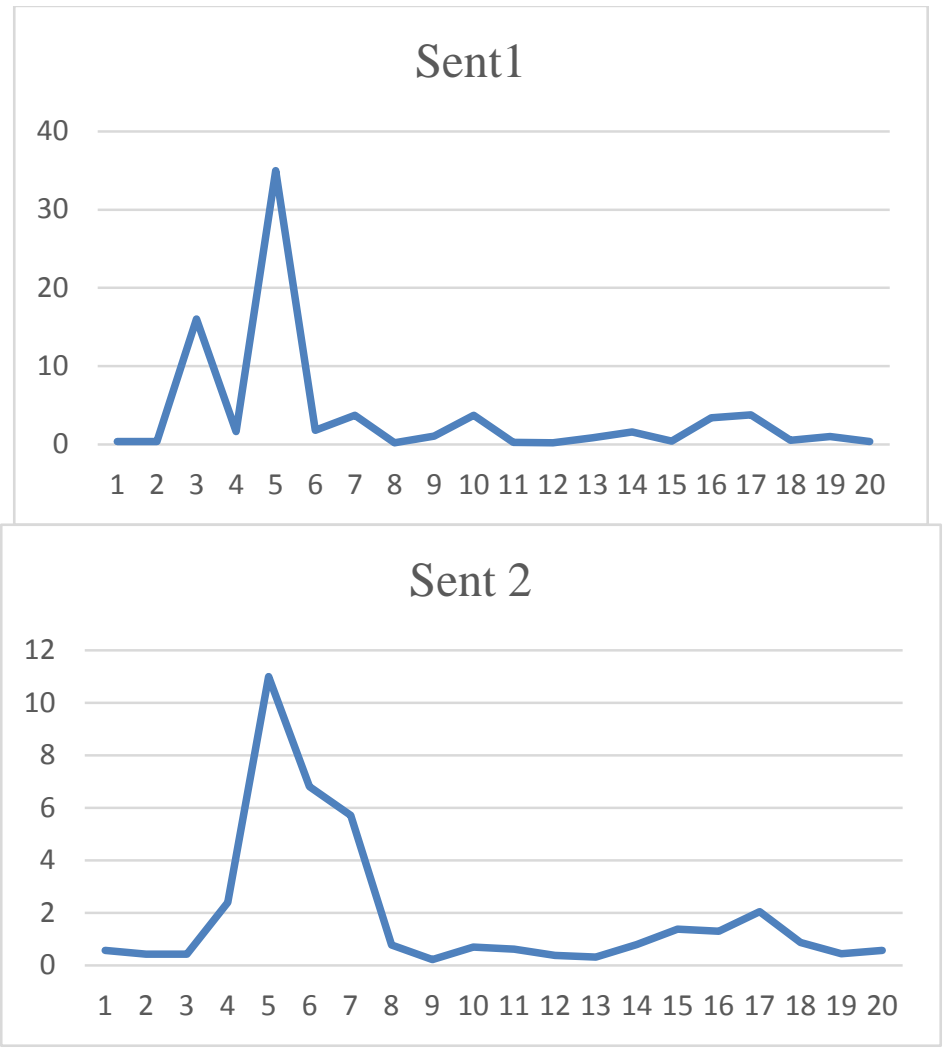

Figure 4.2: Evolution of sentiments measurement indicators

These curves illustrate the evolution of sentiment indicators over the period from 2001 to 2020 . The results show a sharp drop in sentiment indicators in the years 2001-2002; 2007-2009; 2011-2012 and 2019-2020. These years coincide with the stock market crises that affected Morocco, namely: the internet crisis, subprime, the February 20th movement and coronavirus. This allows us to conclude that "the investor sentiment indicator is consistent with stock market crises".

\subsection{The relationship and causal link between crises and feelings}

Before proceeding with the "Granger" test to study the causality link between stock market crises and the sentiment of the Moroccan investor, we have first to check if there is any long-term relationship between these two variables. To do so, we will use "Johansen" co integration test. There is only one co integration in case of non- stationary variables. The first phase of this study thereof consists of studying non-stationary (or the presence of a unit root) of the variables by proceeding to Dickey- Fuller Augmented test.

\subsubsection{Stationary test}

Before answering the question of the existence or not of such a co integration relation, it is necessary to test the nonstationary of the series studied. There are a large number of unit root tests, the pioneering work in this area is that of fuller (1976) and Dickey-Fuller $(1979,1981)$ [19], [20]. The Dickey-Fuller tests are mostly applied because of their simplicity, but they suffer from some criticisms.

\section{Test procedure:}

This procedure consists in testing the following hypotheses:

Ho: level series is not stationary.

H1: level series is stationary. 
International Journal of Advances in Scientific Research and Engineering (ijasre), Vol 7 (3), March -2021

Table 4.1. Results of stationarity Test.

\begin{tabular}{|c|c|c|c|c|c|}
\hline \multirow{2}{*}{ Variables } & \multicolumn{2}{|c|}{ Model 3 (Intercept and Trend) } & \multicolumn{2}{|c|}{ Model 2 (Intercept) } & \multirow{2}{*}{\begin{tabular}{|l} 
Model 1 (None) \\
Unit Root
\end{tabular}} \\
\hline & Trend & Unit Root & Trend & Unit Root & \\
\hline Sent 1 & 1.906559 & 0.0026 & 2.007802 & 0.0023 & $0.0975 * *$ \\
\hline Sent 2 & 2.357093 & 0.0433 & 1.834698 & $0.1075 * *$ & \\
\hline MASI & -0.939365 & $0.0821 * *$ & & & \\
\hline
\end{tabular}

**: Significant at $5 \%$ threshold.

The table above brings together the probabilities for two sentiment indicator series (sent1, sent2) and the MASI stock index. We can clearly notice that the probabilities for sent1, sent2 series and MASI are significantly higher than the critical values of the test, thus the presence of a unit root (PI-value $>=0,5$ ), allowing to accept the null hypothesis of the non- stationarity of the studied series and to reject hypothesis1.

Consequently, we can assume that there a long-term relationship between stock market crises and the investor sentiment. We will verify this relationship using Johansen cointegration test.

\subsubsection{Johansen Cointegration Test}

The starting point of cointegration test resides in the fact that several macro economical and financial series are nonstationary. That is to say, their movement does not halt in time, they can be random or permanent.

The first phase allowed to test the non-stationarity of the two series, whereas in the second phase we will attempt to show that there is a long-term relationship between the variables so as to apply Johansen cointegration test.

This test is based on the eigenvalues of a matrix resulting from the estimation of maximum likelihood parameters by calculating the following Johansen statistics:

$$
\text { Trace }=T-\sum_{i=r+1}^{n} \log \left(1-\lambda_{i}\right)
$$

With:

T: Number of observations; $\lambda_{i}$ : The highest eigenvalue.

The hypotheses are:

\section{Ho: The presence at least of one cointegration relationship.}

\section{H1: Absence of cointegration between series.}

Decision rule of Johansen cointegration test:

For a given significance threshold, the null hypothesis that there is a cointegration relationship between the variables of the model is accepted, if value of the trace is lower than its tabulated value (OSTERWALD-LENUM, 1992 [21]. A trace value higher than its critical value entails on the other hand that there is no cointegration relationship between variables.

\section{Cointegration test between MASI and Sent1:}

The application of Johansen test allows us to draw up the table below: 
International Journal of Advances in Scientific Research and Engineering (ijasre), Vol 7 (3), March -2021

Table 4.2. The result of cointegration test between MASI and sent 1

\begin{tabular}{|l|l|l|l|}
\hline $\begin{array}{l}\text { Number of cointegration } \\
\text { relations }\end{array}$ & Eigenvalue & Statistical Trace & Critical value \\
\hline None* & 0.820807 & 38.91087 & 25.87211 \\
\hline More than 1 & 0.357522 & 7.963608 & 12.51798 \\
\hline
\end{tabular}

*indicates that we should reject $\mathrm{H1}$ and go to the second iteration.

The table below brings together trace tests and the critical values for the series under study (MASI and Sent 1). We notice that the trace is lower than the given critical value $((\lambda=7.963608<12.51798)$, we accept $\mathrm{H} 0$, thus a cointegration relationship between sentiment indicator and the stock market index.

We can verify this by calculation the trace:

For $\mathrm{r}=1, \mathrm{~T}=19, \lambda_{2}=0.357522$

Trace $=-19 \log (1-0.357522)=7.963608<12.51$

We will now study the cointegration between stock market crises and sentiment using the second sentiment indicator (Sent2).

\section{Cointegration test between MASI and Sent2:}

The application of Johansen test allows us to draw up the table below:

Table 4.3: Result of cointegration Test between MASI et sent 2

\begin{tabular}{|l|l|l|l|}
\hline $\begin{array}{l}\text { Number of cointegration } \\
\text { relations }\end{array}$ & Eigenvalue & Statistical Trace & Critical value \\
\hline None* & 0.865828 & 45.29224 & 25.87211 \\
\hline More than 1 & 0.398062 & 9.136819 & 12.51798 \\
\hline
\end{tabular}

*Indicates that we should reject $\mathrm{H1}$ and go to the second iteration.

The table above brings together trace tests and the critical values for the series to study (MASI and Sent2). We note that the trace is less than the given critical value $(\lambda=9.1368191<12.51798)$, we accept H0, thus the existence of at least one of cointegration relationship between investor sentiment and the stock market index.

This can be verified this by trace calculation:

For $\mathrm{r}=1, \mathrm{~T}=19, \lambda_{2}=0.398062$

Trace $=-19 \log (1-0.398062)=9.136819<12.51$

We note that the attained results are the same as Sent1. Cointegration test show the existence of that a long-term relationship between crises and sentiments, two cointegrated variables, that is to say they move in the same direction.

\subsubsection{Causality Test}

After showing that crises and investor sentiment are cointegrated, the problem now is to study the causality link between these two variables. In other words, to answer the following question: Does a crisis engender sentiment or quite the opposite? We apply in this case Granger Causality Test.

"Causality for Granger (1969) between X and Y means the prevision of Y based on the knowledge of lagged values of $\mathrm{X}$ and $\mathrm{Y}$ is more statistically significant than the forecast founded only on lagged values of $\mathrm{Y}$ " [22]. 
International Journal of Advances in Scientific Research and Engineering (ijasre), Vol 7 (3), March -2021

\section{Causality test hypotheses are:}

H0: Sentiment does not cause index

H1: Sentiment causes index

Causality test between MASI and Sent1:

Applying Granger Causality Test allows drawing up the table below:

Table 4.4: Result of causality test between MASI and sent 1

\begin{tabular}{|l|l|l|}
\hline Null hypothesis & Fisher statistics & Probability \\
\hline Sent 1 does not cause MASI & 13.7443 & 0.0006 \\
\hline MASI does not cause sent 1 & 1.18836 & 0.3358 \\
\hline
\end{tabular}

The table above brings together causality probabilities between the series under study (MASI and Sent1). We note that sentiment causes index to a probability of $33.58 \%$. Thus, $\mathrm{H} 1$ is rejected and $\mathrm{H} 1$ is accepted according to which sentiment cause index. We came to the conclusion that "investor sentiment does cause stock market crises".

\section{Causality test between MASI and Sent2:}

Applying Granger Causality Test allow to draw up the table below:

Table 4.5. Result of causality test between MASI and sent 2

\begin{tabular}{|l|l|l|}
\hline Null hypothesis & Fisher statistics & Probability \\
\hline Sent 1 does not cause MASI & 14.24449 & 0.0005 \\
\hline MASI does not cause sent 1 & 0.58493 & 0.5712 \\
\hline
\end{tabular}

The table above summarizes causality probabilities between the studied series (MASI and Sent2). We note that sentiment causes index to a probability of 57.12\%. Therefore, we reject $\mathrm{H}_{\mathrm{o}}$ and accept $\mathrm{H} 1$ for which sentiment causes index. We have managed to verify that "sentiment does in fact cause stock market crisis".

The results obtained show that causality probability between Sent 2 and MASI $(\mathrm{p}=57,12 \%)$ is higher than that of Sent 1 and MASI ( $\mathrm{p}=33.58 \%$ ). We then can assume that Sent 2 explains better the causality link between the sentiment of the Moroccan investor and the crises that hit the Moroccan stock market.

\section{CONCLUSION}

The emergence of behavioural finance has made it possible to introduce the psychological component into financial analysis in order to better understand market price fluctuations and to better explain the anomalies observed on the markets. Within the framework of behavioural studies and with the aim of shedding light on the role of investors and their contribution to the development of stock market crises, we have studied the relationship between investor sentiment and the occurrence of stock market crises over the period 2000-2020.

In order to do this, we have first of all identified the stock market crises which have affected the Moroccan stock market over the period 2000-2020, and then we have proceeded to define investor sentiment and to determine the different measurement indicators which can synthesise the latter. We managed to show that the sentiment indicator fell in the years of crises, so we concluded that "the investor sentiment indicator is consistent with stock market crises". We also used the Granger test to study the causal link between stock market crises and Moroccan investor sentiment and concluded that "investor sentiment causes stock market crises". Hence, the manifestation of the important role played by investor sentiment in the apprehension of stock market crises not explained by traditional financial theory. 
International Journal of Advances in Scientific Research and Engineering (ijasre), Vol 7 (3), March -2021

\section{REFERENCES}

[1] D. Kahneman and A. Tversky, "Prospect Theory: An Analysis of Decision under Risk," Source Econom., vol. 47, no. 2, pp. 263-292, 1979.

[2] Fischer Black, “Noise,” J. Finance, vol. XLI, no. 3, pp. 528-543, 1986.

[3] D. L. J. Bradford, A. Shleifer, S. Lawrence H., and J. W. Robert, "Noise Trader Risk in Financial Markets," J. Polit. Econ., vol. 98, no. 4, pp. 703-738, 1990.

[4] K. Daniel, D. Hirshleifer, and A. Subrahmanyam, "Investor psychology and security market under- and overreactions," J. Finance, vol. 53, no. 6, pp. 1839-1885, 1998.

[5] N. Barberis, A. Shleifer, and R. W. Vishny, "A model of investor sentiment," Adv. Behav. Financ., vol. 2, pp. 423-459, 1998.

[6] Shiller, RJ, “'Do Stock Prices Move too much to be justified by Subsequent Changes in Dividend," Am. Econ. Rev., vol. 71, no. 3, pp. 421-436, 1981.

[7] R. Shiller, "Inneficient markets: An introduction to behavioral finance.," J. bussines 1, pp. 173-174, 2000.

[8] R. Thaler, “The end of Behavioral Finance,” Pap. Assoc. Invest. Manag. Res., 1999.

[9] M. Mangot, Les Comportements en Bourse : 6 Erreurs Psychologiques qui Cô̂tent Cher. 2004.

[10] R. Thaler, “Advances in Behavioral Finance,” Russel Sage Found. , New York, vol. 1, 1993.

[11] G. Linter, "What are the Destinctive Features of Behavioral Finance as Applied to Individual Investor's Desicion-making ?," Int. Proc. Econ. Dev. Res., vol. 21, p. 19, 1998.

[12] O. Robert, "Behavioral Finance and Its Implications for Stock-Price Volatility," Financ. Anal. J., vol. 54, pp. $8-10,1998$.

[13] J. S. Robert, "From Efficient Markets Theory to Behavioral Finance," J. Econ. Perspect., vol. 17, no. 1, pp. 83-104, 2003.

[14] S. Martin, "Behavioural finance," Univ. Cambridge, no. May, pp. 1-14, 2007.

[15] G. Coudret and Gex.M, "Does risk Aversion Drive Financial Crises? Testing the predictive power of Empirical Indicator," Cent. d'études Prospect. d'informations Int., 2006.

[16] M. Reggiani, "Risque de bulle financière sur le marché américain des actions : analyse fondamentale de grosses capitalisations boursières et comparaison historique," Haute Ec. Gest. Génève, 2018.

[17] K. . Fisher and M. Statman, "Consumer Confidence and Stock Returns," J. Portf. Manag., pp. 115-127, 2003.

[18] G. W. Brown and M. T. Cliff, "Investor sentiment and the near-term stock market," J. Empir. Financ., vol. 11, no. 4, pp. 627-628, 2004. 
[19] D. and W. A. F. DAVID A, "Likelihood Ratio Statistics for Autoregressive Time Series with a Unit Root," Econometrica, vol. 49, no. 4, pp. 1057-1072, 1981.

[20] D. David A and F. Wayne A, "Distribution of the Estimators for Autoregressive Time Series with a Unit Root," J. Am. Stat. Assoc., vol. 74, no. 336a, pp. 427-431, 1979.

[21] O.-L. Michael, "A Note with Quantiles of the Asymptotic Distribution of the Maximum Likelihood Cointegration Rank Test Statistics,” Oxford Bull. Econ. Stat., vol. 54, no. 3, pp. 461-472, 1992.

[22] C. J. W. Granger, "Investigating Causal Relations by Econometric Models and Cross-spectral Methods," Econometrica, vol. 37, no. 3, pp. 424-438, 1969. 